\title{
Application of the EQ-5D in the Middle East: A Systematic Review Focusing on Patients Living in the Kingdom of Saudi Arabia
}

\author{
Abdullah Althemery (D) \\ Clinical Pharmacy Department, College \\ of Pharmacy, Prince Sattam Bin Abdulaziz \\ University, Al-Kharj, Al Riyadh Province, \\ Saudi Arabia
}

\begin{abstract}
Patients' quality of life (QoL) and reported outcomes are critical indicators of the burden of a disease and the benefits of healthcare intervention. This systematic review explores publications that have adapted the EQ-5D for use with a population living in Saudi Arabia. The review of the following databases: MEDLINE, EMBASE, Wiley's Database, EBSCO, and ClinicalTrials.gov was conducted on December 1, 2020. The search strategy was adapted from the SPIDER search tool, and the included articles were classified by author, year of publication, region, disease of interest, sample size, type of EQ-5D, and format. Level of EQ-5D was classified as either $3 \mathrm{~L}$ or $5 \mathrm{~L}$. Thirteen articles met the search inclusion criteria. The earliest publication was conducted in 2015 and the latest in 2020 . These studies were conducted in four Saudi administrative regions, and multiple conditions or treatments were studied, the most studied condition being diabetes mellitus, followed by musculoskeletal disorders, back pain, and injuries. This systematic review article finds that the EQ-5D has been well adapted in the KSA. However, continued work is needed to investigate the quality of life for major conditions such as cardiovascular disease and cancer. Moreover, QoL research is lacking in certain regions, such as southern and northern Saudi Arabia. Despite the successful application and validation of the EQ-5D, a local QoL tool is needed to capture the unique context of patients within the healthcare system in the Middle East.
\end{abstract}

Keywords: EQ-5D in the Middle East, QoL in the KSA, health utilities

\section{Introduction}

The EQ-5D tool is used to deliver patient-reported outcomes (PROs) by measuring health status. ${ }^{1}$ It was developed by the Research Foundation and an association of groups under the EuroQol umbrella. ${ }^{1}$ Patients' quality of life (QoL) and reported outcomes are critical indicators of the burden of a disease and the benefits of healthcare intervention. ${ }^{2}$ These measurements are key parameters for decision making based on pharmacoeconomic analysis. ${ }^{2}$ Many international health technology assessment (HTA) bodies have adapted PROs as part of their decision making process, and this has resulted in EQ-5D becoming one of the world's most used tools. $^{3-5}$ For example, the National Institute for Health and Care Excellence in the United Kingdom prefers the EQ-5D and has adopted a specific methodology for its use. $^{3}$

The main domains covered are mobility, usual activities, self-care, pain and discomfort, and anxiety and depression, as reflected by the five in the name EQ-5D.

\footnotetext{
Correspondence: Abdullah Althemery

Tel +966 II 5886000

Fax +966 II 588600 I

Email a.althemery@psau.edu.sa
} 
The EQ-5D can be administered in different formats, including using paper, smartphones, laptops, or more. ${ }^{1}$ All answers are self-reported, and a range of responses are collected that reflect the degree of problem patients face in each domain depending on the survey's level of use; 3L or 5L. Beyond these domains, the EQ-5D scales QoL on a visual analog ranging from 0 , or the worst health respondents can imagine, to 100 , or the best. ${ }^{1,6}$ These collected answers give health practitioners and policymakers health scores other than the traditional surrogate endpoints. ${ }^{7}$ The EQ-5D's importance has seen it translated into numerous languages and dialects. ${ }^{8}$ Additionally, researchers have applied various validation techniques to all aspects of the QoL tool. ${ }^{9-11}$

The EQ-5D is a generic measure of QoL, applicable to a variety of disease conditions and states. ${ }^{1}$ The EuroQol group set out to develop a brief and practical questionnaire that would allow researchers to compare different patient populations, ${ }^{12}$ and many researchers have indeed applied EQ-5D to a range of diseases, treatments, and measurements. ${ }^{13-15}$ Although some researchers have used the EQ-5D with a Middle Eastern population, much of the literature focuses on Western societies. ${ }^{15}$ Healthcare Utilities should be calculated based on specific populations, considering that sociodemographic context could influence QoL scores. ${ }^{16,17}$ Accordingly, this systematic review explores publications that have adapted the EQ$5 \mathrm{D}$ for use with a population living in Saudi Arabia.

\section{Materials and Methods}

A systematic review was conducted on December 1, 2020, of the following databases: MEDLINE, EMBASE, Wiley's Database, EBSCO, and ClinicalTrials.gov. The search strategy was adapted from the SPIDER search tool and is detailed in Table $1 .{ }^{18}$ All identified titles and abstracts were scanned to confirm that the associated article met the inclusion criteria, which was that it had to be an original article published fully and conducted in the KSA using the EQ-5D instrument to describe a medical

Table I Description of SPIDER Search Tool

\begin{tabular}{|l|l|}
\hline SPIDER & Description \\
\hline Sample & Population from Saudi Arabia \\
Phenomenon of Interest & Comorbid condition or treatment \\
Design & Quantitative data \\
Evaluation & Used EQ-5D instrument \\
Research type & Original article; full article \\
\hline
\end{tabular}

condition or treatment. Articles' reports of the descriptive part of the EQ-5D instrument or the visual analog score were then scanned.

Ultimately thirteen articles were identified. Figure 1 shows the articles included and excluded after application of the SPIDER tool. Included articles were classified by author, year of publication, region, disease of interest, sample size, type of EQ-5D, and format. Year of publication was adapted to ensure a uniform comparison, as some studies had been conducted during different calendar years. Region was identified by linking the site of the study to Saudi Arabia's thirteen official administrative regions. ${ }^{19}$ Level of EQ-5D was classified as either $3 \mathrm{~L}$ or 5L. EQ-5D levels were established earlier, reflecting three levels of each of the five dimensions measured: no problems, small or moderate problems, and extreme problems. The $3 \mathrm{~L}$ yields in maximum of health status that was equivalent to $243,{ }^{20,21}$ whereas the five-level EQ-5D was established later, indicating no, slight, moderate, severe, or extreme problems, summing to a health status of $3125 .^{20,21}$

We focused on three themes of analysis when comparing the selected articles: patient population, time, and place. Our approach was inspired by the work of Costanza et al. $^{22}$ According to them, QoL is a multidimensional theory that captures multiple needs for individuals, communities, nations, and global use. A QoL scale should thus be designed to capture a value for a group of people in a certain place at a certain time. ${ }^{22}$ In our review, we compare our selected articles quantitatively and qualitatively across different diseases, publication times, and country regions.

\section{Results and Discussion}

Thirteen articles met the search inclusion criteria. The earliest publication was conducted in 2015 and the latest in 2020. These studies were conducted in four Saudi administrative regions, and multiple conditions or treatments were studied. Table 2 shows the characteristics of the reviewed studies.

\section{Comparison of Results by Condition or Treatment}

The most studied condition was diabetes mellitus $(n=4),{ }^{23-26}$ followed by musculoskeletal disorders, back pain, and injuries $(n=3) .{ }^{27-29}$ The remaining articles focused either on a specific condition, such as urinary 


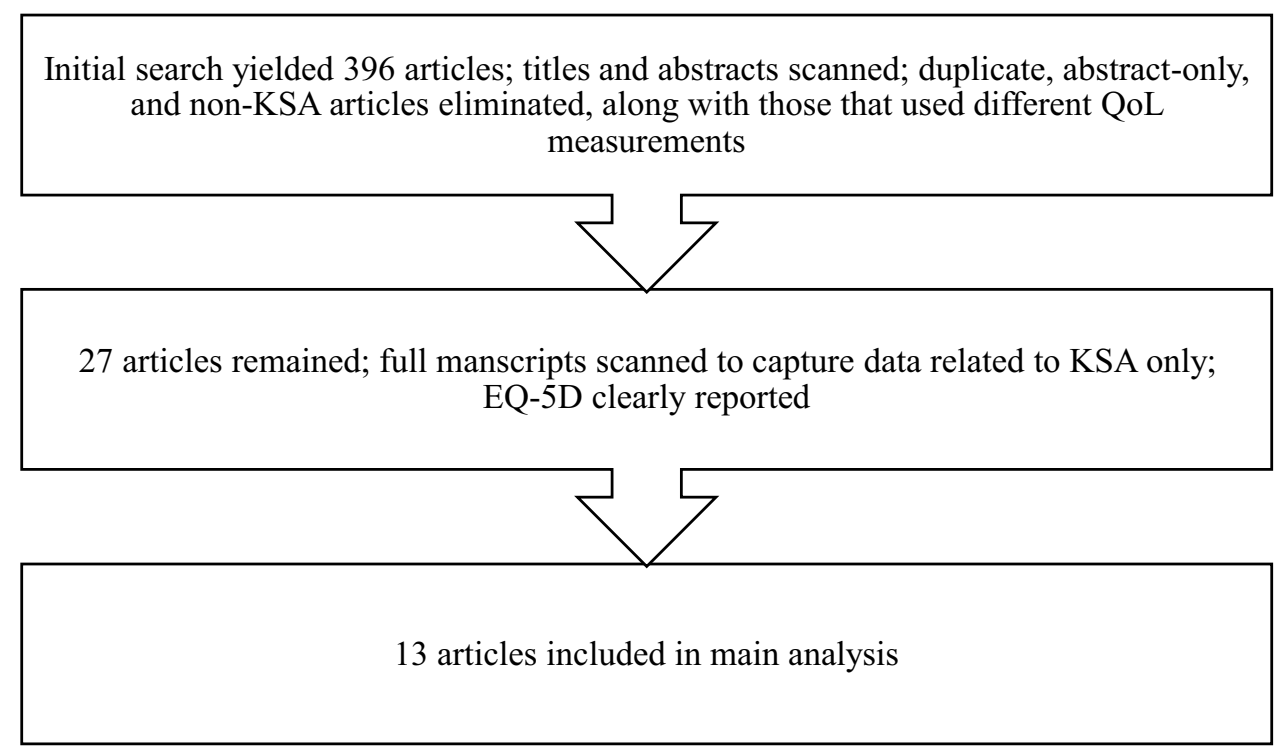

Figure I Article selection process.

tract infections, ${ }^{30}$ chronic obstructive pulmonary disease, ${ }^{31}$ or multiple sclerosis; $^{32}$ on a treatment, such as teriparatide, ${ }^{33}$ warfarin, or apixaban; ${ }^{34}$ or on a nonspecific condition. ${ }^{35}$ For all the reviewed studies, only one study reported the Cronbach's alpha value of 0.72 , which could indicate an acceptable reliability and an opportunity for enhancement. ${ }^{35}$

The sample size of each study was related to the condition of interest. Out of a summed sample equal to 2025 patients, 36\% had diabetes, ${ }^{23-26}$ —unsurprising considering that the prevalence of diabetes in the KSA exceeds $14 \%$ of the population. ${ }^{36}$ The second largest sample study was patients who had cardiovascular diseases, which also affect millions in the KSA. ${ }^{36}$

Four articles reported EQ-5 dimensions and covered two medical conditions, diabetes and multiple sclerosis. For the diabetes studies, the results were consistent, with the majority of enrolled patients reporting no problems with mobility, self-care, usual activities, or anxiety and depression. However, a high percentage of patients who had diabetes reported slight problems with pain and discomfort. A higher percentage of patients with multiple sclerosis reported extreme difficulties with mobility, selfcare, usual activities, anxiety and depression, and pain and discomfort.

Interestingly, some local quality-of-life figures align with international results obtained using the EQ-5D. Saudi patients who had atrial fibrillation reported an average EQVAS score of 67.99. Similarly, Brüggenjürgen et al collected
EQ-VAS scores from the European Registry in Atrial Fibrillation (PREFER in AF) and obtained a similar average score of $68.80 .{ }^{37}$ By contrast, Alanazi (2020) explored QoL in women treated for UTI and reported a utility index of 0.524 , lower than those reported in international studies and equivalent to females who had a resistant UTI (0.565), as reported by Abrahamian et al (2011), whose study was conducted in the United States and used SF-36, mapped to the EQ-5D index. ${ }^{38,39}$

\section{Comparison of Results by Date}

A chronological review of the data reveals an increase in research using the QoL tool between 2015 and 2020. The first publication concerning the EQ-5D in the KSA appeared in 2015, with another following in 2017. About two-thirds of the reviewed publications were released in 2020. Moreover, the average VAS score has increased, with patients who had type 2 diabetes scoring 71 in 2020 compared with a score of 68.5 in 2015. These results indicate growing interest among Saudi scholars in patients' QoL. Indeed, great investments have been made in the Saudi healthcare system infrastructure, with QoL a major indicator of return on investment.

Another important explanation for the increased number of publications using EuroQol is its availability in an Arabic format. Alaboudi (2016) explored the QoL using the EQ-5D in a form produced by a group of local translators. ${ }^{26}$ Translating a QoL tool can be an imposing additional challenge for a researcher and requires 
Table 2 Characteristics of the Reviewed Articles

\begin{tabular}{|c|c|c|c|c|c|c|}
\hline Article & Year & Region & Disease & $\begin{array}{l}\text { Sample } \\
\#\end{array}$ & $\begin{array}{l}\text { Type of } \\
\text { EQ-5D }\end{array}$ & Format \\
\hline Algarni et $\mathrm{al}^{27}$ & 2020 & Makkah (Taif) & Musculoskeletal disorders & 153 & $\begin{array}{l}\text { EQ-5D- } \\
3 \mathrm{~L}\end{array}$ & $\begin{array}{l}\text { Self-report } \\
\text { questionnaire }\end{array}$ \\
\hline $\begin{array}{l}\text { Alshayban and } \\
\text { Joseph }^{23}\end{array}$ & 2020 & Eastern Province & Type 2 diabetes & 378 & $\begin{array}{l}\text { Q-5D- } \\
5 \mathrm{~L}\end{array}$ & Interview \\
\hline Althemery et al $\left.\right|^{34}$ & 2020 & Riyadh & AF patients & 388 & $\begin{array}{l}\text { Q-5D- } \\
5 \mathrm{~L}\end{array}$ & Paper \\
\hline Elsalmawy et $\mathrm{al}^{33}$ & 2020 & Not specified & Patients using Teriparatide $\mathrm{F}$ & 364 & $\begin{array}{l}\text { EQ-5D- } \\
5 \mathrm{~L}\end{array}$ & $\begin{array}{l}\text { Self-report } \\
\text { questionnaire }\end{array}$ \\
\hline Abdelbasset et $\mathrm{al}^{28}$ & 2020 & Alkharj; & Chronic nonspecific low back pain & 60 & $\begin{array}{l}\text { EQ-5D- } \\
3 \mathrm{~L}\end{array}$ & $\begin{array}{l}\text { Self-report } \\
\text { questionnaire }\end{array}$ \\
\hline Alanazi $^{30}$ & 2020 & Riyadh & Urinary tract infection & $|3|$ & $\begin{array}{l}\text { EQ-5D- } \\
3 \mathrm{~L}\end{array}$ & $\begin{array}{l}\text { Self-report } \\
\text { questionnaire }\end{array}$ \\
\hline Almasri et $\mathrm{al}^{24}$ & 2020 & Jeddah & Type 2 diabetes & 339 & $\begin{array}{l}\text { Q-5D- } \\
5 \mathrm{~L}\end{array}$ & Interview \\
\hline Alghnam et $\mathrm{al}^{29}$ & 2020 & Riyadh & Blunt trauma & 249 & $\begin{array}{l}\text { EQ-5D- } \\
5 L\end{array}$ & Interview \\
\hline Gelhorn et $\mathrm{al}^{25}$ & 2020 & $\begin{array}{l}\text { Jeddah, Riyadh, and } \\
\text { Dammam }\end{array}$ & Type 2 diabetes & 310 & $\begin{array}{l}\text { EQ-5D- } \\
5 L\end{array}$ & $\begin{array}{l}\text { Self-report } \\
\text { questionnaire }\end{array}$ \\
\hline Bekairy et al ${ }^{35}$ & 2018 & Riyadh & No specific disease & 80 & $\begin{array}{l}\text { EQ-5D- } \\
3 \mathrm{~L}\end{array}$ & Interview \\
\hline Kokturk et $\mathrm{al}^{3 \mathrm{I}}$ & 2018 & All & $\begin{array}{l}\text { Chronic obstructive pulmonary } \\
\text { disease }\end{array}$ & 206 & $\begin{array}{l}\text { EQ-5D- } \\
3 \mathrm{~L}\end{array}$ & Self-report tool \\
\hline Algahtani et $\mathrm{al}^{32}$ & 2017 & Jeddah & Multiple sclerosis & 292 & $\begin{array}{l}\text { EQ-5D- } \\
5 \mathrm{~L}\end{array}$ & Interview \\
\hline Al-Aboudi et $\mathrm{al}^{26}$ & 2015 & Riyadh & Type 2 diabetes & 75 & $\begin{array}{l}\text { EQ-5D- } \\
3 \mathrm{~L}\end{array}$ & Self-report tool \\
\hline
\end{tabular}

a substantial budget. ${ }^{40}$ In recent years, EuroQol has made an Arabic-format version of the EQ-5D readily available, with many researchers validating and modifying the tool, even to the point of covering certain Arabic dialects. ${ }^{35,41}$ At the end of 2020, more than 109 EQ-5D tools were available for different dialects and platforms. ${ }^{42}$

\section{Comparison of Results by Region}

Only three of the thirteen official administrative Saudi Arabian regions have been studied: Riyadh, ${ }^{26,29,30,34}$ Makkah, ${ }^{24,27,32}$ and Dammam. ${ }^{23}$ Riyadh likely accounts for more publications, being the capital of the KSA and home to many hospitals and universities. ${ }^{43,44}$ Diabetes mellitus was studied across three regions: Riyadh,
Jeddah, and Dammam. Generally, average EQ-5D scores were similar, but females living in the Riyadh region had lower EQ-5D scores than those living in Jeddah. $^{24,26}$

Most studies used the Arabic (Saudi) format of the EQ-5D, but they differed in how they administered the survey. Regions other than Riyadh relied on an interviewer administering the survey, whereas studies from the Riyadh region were mostly conducted through selfadministration on paper. Even so, results for similar conditions were equivalent. It is worth noting that the EQ-5D is designed to be self-reported by patients, and an interviewer administrating it might introduce a "Hawthorne Effect," where participants' answers 
could be influenced by the presence of the interviewer. $^{45}$

One important finding is the lack of research on QoL for patients living in northern and southern Saudi Arabia. The Saudi government has announced a new transformative vision for 2030, one of which is to improve the quality of healthcare while maintaining the efficacy of spending. ${ }^{46}$ Continued investigation of QoL is thus needed, particularly for underserved regions.

\section{Conclusion}

This systematic review article finds that the EQ-5D has been well adapted in the KSA. However, continued work is needed to investigate the quality of life because QoL currently focuses on conditions such as diabetes even though major conditions such as cardiovascular disease and cancer remain poorly studied. Moreover, QoL research is lacking in certain regions, such as southern and northern Saudi Arabia. Despite the successful application and validation of the EQ-5D, a local QoL tool is needed to capture the unique context of patients within the healthcare system in the Middle East.

\section{Acknowledgments}

I'd like to thank the Deanship of Scientific Research at Prince Sattam bin Abdulaziz University. Also, I'd like to thank the independent reviewers, Dr. Abdullah Alfaifi and Dr. Nehad Jasser for validating the methods.

\section{Disclosure}

The author reports no conflicts of interest in this work.

\section{References}

1. van Reenen M, Janssen B. EQ-5D-5L User Guide Basic Information on How to Use the EQ-5D-5L Instrument. Rotterdam EuroQol Research Foundation; 2019.

2. Rascati KL. Essentials of Pharmacoeconomics. Baltimore: Lippincott Williams \& Wilkins; 2008.

3. National Institute for Health and Care Excellence. Position statement on use of the EQ-5D-5L value set for England; 2019. Available from: https://www.nice.org.uk/about/what-we-do/our-programmes/niceguidance/technology-appraisal-guidance/eq-5d-51. Accessed April 22, 2021.

4. Devlin N, Parkin D, Janssen B. An introduction to EQ-5D instruments and their applications. In: Methods for Analysing and Reporting EQ5D Data. Springer; 2020:1-22.

5. Pre-authorisation Evaluation of Medicines for Human Use. Reflection paper on the regulatory guidance for the use of health-related quality of life (HRQL) measures in the evaluation of medicinal products. Eur Med Agency. 2005.

6. Balestroni G, Bertolotti G. [EuroQol-5D (EQ-5D): an instrument for measuring quality of life]. Monaldi Arch Chest Dis. 2012;78 (3):155-159. doi:10.4081/monaldi.2012.121
7. Appleby J, Devlin N, Parkin D. Using Patient Reported Outcomes to Improve Health Care. John Wiley \& Sons; 2015.

8. EuroQol Research Foundation. EQ-5D-5L; 2020. Available from: https://euroqol.org/eq-5d-instruments/eq-5d-51-available-modes-ofadministration/self-complete-on-paper/. Accessed April 22, 2021.

9. Vartiainen P, Mäntyselkä P, Heiskanen T, et al. Validation of EQ-5D and 15D in the assessment of health-related quality of life in chronic pain. Pain. 2017;158(8):1577-1585. doi:10.1097/j. pain.0000000000000954

10. Encheva M, Djambazov S, Vekov T, Golicki D. EQ-5D-5L Bulgarian population norms. Eur $J$ Health Econ. 2020;21(8):1169-1178. doi:10.1007/s10198-020-01225-5

11. Aburuz S, Bulatova N, Twalbeh M, Gazawi M. The validity and reliability of the Arabic version of the EQ-5D: a study from Jordan. Ann Saudi Med. 2009;29(4):304-308. doi:10.4103/0256-4947.55313

12. Devlin NJ, Brooks R. EQ-5D and the EuroQol group: past, present and future. Appl Health Econ Health Policy. 2017;15(2):127-137. doi:10.1007/s40258-017-0310-5

13. Lum E, McCreanor V, Luo N, Graves N. Quality of life measured by EQ-5D at different treatment time points for coronary artery disease: protocol for a systematic review and meta-analysis. BMJ Open. 2020;10(7):e039311. doi:10.1136/bmjopen-2020-039311

14. Ara R, Brazier J. Comparing EQ-5D scores for comorbid health conditions estimated using 5 different methods. Med Care. 2012;50 (5):452-459. doi:10.1097/MLR.0b013e318234a04a

15. Xie F, Gaebel K, Perampaladas K, Doble B, Pullenayegum E. Comparing EQ-5D valuation studies: a systematic review and methodological reporting checklist. Med Decis Making. 2014;34(1):8-20. doi:10.1177/0272989X13480852

16. Busschbach J, Weijnen T, Nieuwenhuizen M, et al. A comparison of EQ-5D time trade-off values obtained in Germany, the United Kingdom and Spain. In: The Measurement and Valuation of Health Status Using EQ-5D: A European Perspective. Springer; 2003:143-165.

17. Badia X, Roset M, Herdman M, Kind P. A comparison of United Kingdom and Spanish general population time trade-off values for EQ-5D health states. Med Decis Mak. 2001;21(1):7-16. doi:10.1177/ 0272989X0102100102

18. Methley AM, Campbell S, Chew-Graham C, McNally R, CheraghiSohi S. PICO, PICOS and SPIDER: a comparison study of specificity and sensitivity in three search tools for qualitative systematic reviews. BMC Health Serv Res. 2014;14(1):579. doi:10.1186/ s12913-014-0579-0

19. SOCPA. Regions of the Kingdom; 2015. Available from: https:// socpa.org.sa/Socpa/About-Socpa/About-Kingdom/Regions-of-theKingdom.aspx?lang=en-us. Accessed April 22, 2021.

20. Buchholz I, Janssen MF, Kohlmann T, Feng Y-S. A systematic review of studies comparing the measurement properties of the three-level and five-level versions of the EQ-5D. Pharmacoeconomics. 2018;36(6):645-661. doi:10.1007/s40273-018$0642-5$

21. Crick K, Al Sayah F, Ohinmaa A, Johnson JA. Responsiveness of the anxiety/depression dimension of the 3-and 5-level versions of the EQ-5D in assessing mental health. Qual Life Res. 2018;27 (6):1625-1633. doi:10.1007/s11136-018-1828-1

22. Costanza R, Fisher B, Ali S, et al. An integrative approach to quality of life measurement, research, and policy. S.A.P.I.EN.S; 2008. Available from: http://sapiens.revues.org/169. Accessed January 1, 2012.

23. Alshayban D, Joseph R. Health-related quality of life among patients with type 2 diabetes mellitus in Eastern Province, Saudi Arabia: a Cross-Sectional Study. PLoS One. 2020;15(1):e0227573. doi:10.1371/journal.pone.0227573

24. Almasri DM, Noor AO, Ghoneim RH, et al. The impact of diabetes mellitus on health-related quality of life in Saudi Arabia. Saudi Pharm J. 2020;28(12):1514-1519. doi:10.1016/j.jsps.2020.09.018 
25. Gelhorn HL, Boye KS, Shalhoub H, et al. Patient-reported outcomes and impact of type 2 diabetes: a Cross-Sectional Study in the Kingdom of Saudi Arabia. Patient Prefer Adherence. 2020;14:2231-2242. doi:10.2147/PPA.S265126

26. AL-Aboudi IS, Hassali MA, Shafie AA, Hassan A, Alrasheedy AA. A cross-sectional assessment of health-related quality of life among type 2 diabetes patients in Riyadh, Saudi Arabia. SAGE Open Med. 2015;3:2050312115610129. doi:10.1177/2050312115610129

27. Algarni FS, Alotaibi AN, Altowaijri AM, Al-Sobayel H. Crosscultural adaptation and validation of the Arabic version of musculoskeletal health questionnaire (MSK-HQ-Ar). Int J Environ Res Public Health. 2020;17(14):5168. doi:10.3390/ijerph17145168

28. Abdelbasset WK, Nambi G, Alsubaie SF, et al. A Randomized Comparative Study between high-intensity and low-level laser therapy in the treatment of chronic nonspecific low back pain. Evid Based Complement Alternat Med. 2020;2020:1-6. doi:10.1155/2020/1350281

29. Almarwani S, Hijazi L, Alamer M, et al. The association between family cohesion and disability following blunt trauma: findings from a level-I trauma center in Saudi Arabia. Inj Epidemiol. 2020;7(1). doi:10.1186/s40621-020-00271-0

30. Alanazi MQ. Evaluation of health-related quality of life in women with community-acquired urinary tract infections using the EQ-5D3L in Saudi Arabia. Patient Prefer Adherence. 2020;14:2419-2426. doi:10.2147/PPA.S277367

31. Kokturk N, Polatli M, Oguzulgen IK, et al. Adherence to COPD treatment in Turkey and Saudi Arabia: results of the ADCARE Study. Int J Chron Obstruct Pulmon Dis. 2018;13:1377. doi:10.2147/COPD.S150411

32. Algahtani H, Shirah B, Alzahrani F, Abobaker H, Alghanaim N, Manlangit J Jr. Quality of life among multiple sclerosis patients in Saudi Arabia. Neurosciences. 2017;22(4):261-266. doi:10.17712/ nsj.2017.4.20170273

33. Elsalmawy AA, Al-Ali NS, Yaghi Y, et al. Middle East experience from the Asia and Latin America Fracture Observational Study (ALAFOS): baseline characteristics of postmenopausal women with osteoporosis using teriparatide. J Int Med Res. 2020;48 (8):0300060520940855. doi:10.1177/0300060520940855

34. Althemery AU, Alfaifi AA, Alturaiki A, Ammari MAL, Sultana K, Lai L. A comparison between warfarin and apixaban: a patient's perspective. Ann Thorac Med. 2020;15(2):84-89. doi:10.4103/atm.ATM_352_19

35. Bekairy AM, Bustami RT, Almotairi M, et al. Validity and reliability of the Arabic version of the Euroqol (EQ-5D). Int $J$ Health Sci (Qassim). 2018;12(2):16-20.
36. World Health Organization. Diabetes country profiles; 2016. Available from: https://www.who.int/diabetes/country-profiles/sau_ en.pdf. Accessed April 22, 2021.

37. Brüggenjürgen $B$, Schliephacke $T$, Darius $H$, et al. Health state in patients with atrial fibrillation on new oral anticoagulants as assessed with the new Eq-5d-51 questionnaire at baseline and 12-month follow-up: prefer in Af registry. Value Health. 2014;17(7):A493. doi:10.1016/j.jval.2014.08.1464

38. Bermingham SL, Ashe JF. Systematic review of the impact of urinary tract infections on health-related quality of life. BJU Int. 2012;110 (11c):E830-E836. doi:10.1111/j.1464-410X.2012.11337.x

39. Abrahamian FM, Krishnadasan A, Mower WR, Moran GJ, Coker JR, Talan DA. The association of antimicrobial resistance with cure and quality of life among women with acute uncomplicated cystitis. Infection. 2011;39(6):507-514. doi:10.1007/s15010-011-0163-z

40. Tsang S, Royse CF, Terkawi AS. Guidelines for developing, translating, and validating a questionnaire in perioperative and pain medicine. Saudi J Anaesth. 2017;11(Suppl 1):S80. doi:10.4103/sja. SJA_203_17

41. Papadimitropoulos EA, Elbarazi I, Blair I, Katsaiti M-S, Shah KK, Devlin NJ. An investigation of the feasibility and cultural appropriateness of stated preference methods to generate health state values in the United Arab Emirates. Value Health Reg Issues. 2015;7:34-41. doi:10.1016/j.vhri.2015.07.002

42. EuroQol. Available versions and modes of administration; 2020. Available from: https://euroqol.org/eq-5d-instruments/all-eq-5dversions/. Accessed April 22, 2021.

43. Al-Hashem A. Health education in Saudi Arabia: historical overview. Sultan Qaboos Univ Med J. 2016;16(3):e286-292. doi:10.18295/ squmj.2016.16.03.004

44. Al-Hanawi MK, Khan SA, Al-Borie HM. Healthcare human resource development in Saudi Arabia: emerging challenges and opportunities - a critical review. Public Health Rev. 2019;40(1):1. doi:10.1186/ s40985-019-0112-4

45. Chen S, Burström B, Sparring V, Qian D, Burström K. Differential impact of an education-based intervention for patients with type 2 diabetes mellitus in rural China. Int J Environ Res Public Health. 2019;16(15):2676. doi:10.3390/ijerph16152676

46. Alharbi MF. An analysis of the Saudi health-care system's readiness to change in the context of the Saudi National health-care plan in vision 2030. Int J Health Sci (Qassim). 2018;12(3):83.
Journal of Multidisciplinary Healthcare

\section{Publish your work in this journal}

The Journal of Multidisciplinary Healthcare is an international, peerreviewed open-access journal that aims to represent and publish research in healthcare areas delivered by practitioners of different disciplines. This includes studies and reviews conducted by multidisciplinary teams as well as research which evaluates the results or conduct of such teams or healthcare processes in general. The journal covers a very wide range of areas and welcomes submissions from practitioners at all levels, from all over the world. The manuscript management system is completely online and includes a very quick and fair peer-review system. Visit http://www.dovepress.com/testimonials. php to read real quotes from published authors. 